\title{
Flow Diversion in Ruptured Intracranial Aneurysms: A Meta-Analysis
}

\author{
(D)T.P. Madaelil, (D)C.J. Moran, DD.T. Cross III, and (D)A.P. Kansagra
}

\begin{abstract}
BACKGROUND: Flow diversion is now an established technique to treat unruptured intracranial aneurysms not readily amenable to endovascular coil embolization or open microsurgical occlusion. The role of flow-diverting devices in treating ruptured aneurysms is less clear.
\end{abstract}

PURPOSE: To estimate rates of angiographic occlusion and good clinical outcome in patients with ruptured intracranial aneurysms treated with flow-diverting devices.

DATA SOURCES: Systematic review of Ovid MEDLINE, PubMed, Cochrane databases, and EMBASE from inception to December 2015 for articles that included ruptured aneurysms treated with flow diversion.

STUDY SELECTION: One hundred seventy-two records were screened, of which 20 articles contained sufficient patient and outcome data for inclusion.

DATA ANALYSIS: Clinical and radiologic characteristics, procedural details, and outcomes were extracted from these reports. Aggregated occlusion rates and clinical outcomes were analyzed by using the Fisher exact test (statistical significance, $\alpha=.05$ ).

DATA SYNTHESIS: Complete occlusion of the aneurysm was achieved in $90 \%$ of patients, and favorable clinical outcome was attained in $81 \%$. Aneurysm size greater than $7 \mathrm{~mm}$ was associated with less favorable clinical outcomes $(P=.027)$. Aneurysm size greater than $2 \mathrm{~cm}$ was associated with a greater risk of rerupture after treatment $(P<.001)$.

LIMITATIONS: Observational studies and case reports may be affected by reporting bias.

CONCLUSIONS: Although not recommended as a first-line treatment, the use of flow diverters to treat ruptured intracranial aneurysms may allow high rates of angiographic occlusion and good clinical outcome in carefully selected patients. Aneurysm size contributes to treatment risk because the rerupture rate following treatment is higher for aneurysms larger than $2 \mathrm{~cm}$.

ABBREVIATIONS: $\mathrm{FD}=$ flow diverter; $\mathrm{GOS}=$ Glasgow Outcome Scale

E ndovascular treatment of intracranial aneurysms with detachable coils was first described in $1991^{1}$ and has since become an established method of aneurysm treatment. The International Study of Unruptured Intracranial Aneurysms ${ }^{2}$ and Analysis of Treatment by Endovascular Approach of Nonruptured Aneurysms (ATENA) ${ }^{3}$ demonstrated the effectiveness and relative

Received August 11, 2016; accepted after revision October 11.

From the Mallinckrodt Institute of Radiology (T.P.M., C.J.M., D.T.C., A.P.K.) and Department of Neurosurgery (C.J.M., D.T.C., A.P.K.), Washington University School of Medicine, St. Louis, Missouri.

Please address correspondence to Thomas P. Madaelil, MD, Mallinckrodt Institute of Radiology, Washington University School of Medicine, 510 South Kingshighway Blvd, St. Louis, MO 63110; e-mail: madaelilt@mir.wustl.edu; @AkashKansagra

三 Indicates article with supplemental on-line table.

http://dx.doi.org/10.3174/ajnr.A5030 safety of endovascular coiling for unruptured aneurysms. Similarly, the International Subarachnoid Aneurysm Trial (ISAT), the Barrow Ruptured Aneurysm Trial, and other trials ${ }^{4-7}$ have demonstrated the effectiveness and relative safety of endovascular coiling in ruptured aneurysms.

In recent years, flow diverters (FDs) have emerged as a new endovascular treatment option for intracranial aneurysms. FDs are a reconstructive treatment in which altered flow within an aneurysm induces gradual remodeling and eventual thrombosis of the aneurysm. Several studies have demonstrated good safety and efficacy of FDs for the treatment of unruptured intracranial aneurysms, ${ }^{8-17}$ though the safe use of these devices requires the use of dual antiplatelet therapy. ${ }^{18-20}$

Understandably, the need for antiplatelet medications and the delayed nature of aneurysm thrombosis have tempered en- 
thusiasm for using FDs for ruptured aneurysms. Nevertheless, several reports have described the use of FDs to treat recently ruptured aneurysms, particularly those that are difficult to treat by other endovascular or open microsurgical techniques.

In this meta-analysis, we review the outcomes associated with the use of FDs for the treatment of ruptured intracranial aneurysms. Specifically, we review aneurysm characteristics and endovascular treatment strategies in relation to the rates of angiographic occlusion and good clinical outcome, with the overall goal of guiding FD use in ruptured aneurysms when other treatment options are not viable.

\section{MATERIALS AND METHODS \\ Literature Search}

Systematic review of Ovid Medline, PubMed, the Cochrane Central Register of Controlled Trials, the Cochrane Database of Systemic Reviews, and EMBASE from inception to December 2015 was performed by using the terms "rupture" and "aneurysm" in all permutations with "pipeline embolization," "flow diversion," or "flow diverting stent." The search was restricted to human studies in English. Bibliographies of all studies were also reviewed to identify additional relevant studies.

\section{Eligibility Criteria}

All titles and abstracts were screened for eligibility. Studies that provided patient-level information regarding clinical presentation of subarachnoid hemorrhage, aneurysm characteristics, procedural details, periprocedural complications, occlusion status, and clinical status at last follow-up were deemed eligible. If studies included treatment of both ruptured and unruptured aneurysms, only the information from ruptured aneurysms was included.

\section{Data Synthesis and Analysis}

Following eligibility verification, data were extracted from the manuscript text, patient demographic tables and on-line tables, and figures. These data were entered into a predefined digitized form according to the Preferred Reporting Items for Systematic Reviews and Meta-Analyses: The PRISMA Statement. These data points included patient characteristics of age, sex, and clinical status at admission (Hunt and Hess scale/World Federation of Neurosurgical Societies score, and the Fisher scale); aneurysm characteristics, including type, size, and location; procedural details such as time to treatment and devices used, including the type of FD and adjunctive devices (eg, coils) used before or during FD placement; and outcomes, including periprocedural complications, aneurysmal occlusion status, clinical outcome, and duration of both clinical and angiographic follow-up. Time to treatment was classified as acute if FD placement occurred within 15 days of initial SAH and delayed otherwise. The clinical score at presentation was classified as good for Hunt and Hess/World Federation of Neurosurgical Societies scores of $1-3$ and poor for scores of $4-5 .{ }^{21}$ Clinical outcome was classified by the Glasgow Outcome Scale (GOS) or mRS at last clinical follow-up. Favorable clinical outcome was defined as GOS $=4-5$ or $\mathrm{mRS}=0-2$, and unfavorable clinical outcomes corresponded to GOS $=1-3$ or $\mathrm{mRS}=3-6$.

Data for each patient were analyzed as if all patients belonged

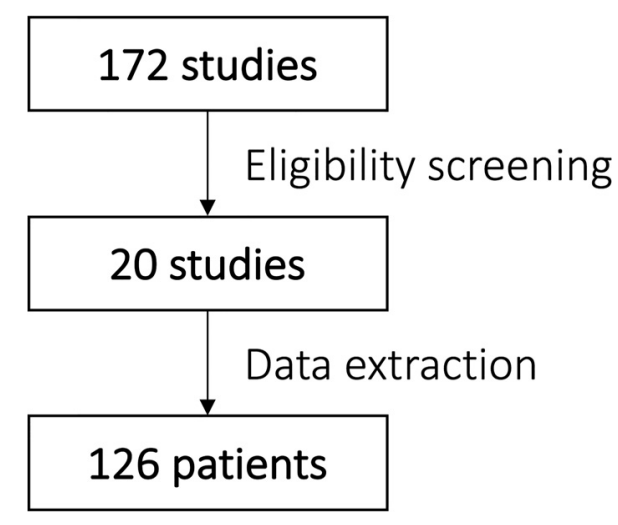

FIG 1. Simplified flowchart of literature search strategy.

to a single cohort. ${ }^{22}$ The association among demographic and clinical risk factors, periprocedural complication rate, occlusion rate based on device selection, and favorable outcome was evaluated by using the Fisher exact and 2-tailed $t$ tests for categorical and continuous variables, respectively. Data are reported as simple proportions. The threshold of statistical significance was $\alpha=$ .05. All statistical analyses were performed by using SPSS, Version 22 (IBM, Armonk, New York) and Excel 2007 (Microsoft, Redmond, Washington).

\section{RESULTS}

\section{Studies and Aneurysm Characteristics}

The initial electronic search yielded 172 records (Fig 1). Large observational studies that shared institutional data bases with smaller reported case series were excluded to prevent case duplication. Studies that did not report individual patient data points were also excluded. Ultimately, 20 observational studies and case reports representing 126 distinct cases met the inclusion criteria (Online Table).

Median age was 51 years (interquartile range, 45-60 years), and $71 \%$ of patients were women. The median Hunt Hess/World Federation of Neurosurgical Societies grading scale at presentation was 2 (interquartile range, $1-3$ ). The median aneurysm size was $3.5 \mathrm{~mm}$ (interquartile range, $2.3-10 \mathrm{~mm}$ ). Five distinct aneurysm morphologies were present, including dissecting $(28 \%, 35 / 125)$, fusiform $(10 \%, 12 / 125)$, giant $(3 \%, 4 / 125)$, blister $(38 \%, 47 / 125)$, and saccular $(22 \%, 27 / 125)$ types. Treated aneurysms were located in the anterior circulation in $64 \%$ (81/126) of cases, and 36\% (45/126) were in the posterior circulation.

\section{Treatment}

In total, $67 \%$ of cases $(84 / 126)$ specified the timing of treatment, with an average time to treatment of 9.6 days (range, $0-60$ days); $74 \%(62 / 84)$ were treated in the acute phase, and 26\% (22/84), in a delayed fashion. The Pipeline Embolization Device (Covidien, Irvine, California) was used for FD-based treatment in 96\% $(121 / 126)$ of cases, while the Silk flow diverter (Balt Extrusion, Montmorency, France) was used in the remaining 4\% (5/126) of cases. Seventy-three percent $(92 / 126)$ of aneurysms were treated with FD placement only, while 27\% (34/126) were treated with a combination of an FD and adjunctive coils. These included 4 cases in which FD-based treatment was implemented after initial unsuccessful treatment with microsurgical clipping or stent-assisted 
Table 1: Angiographic outcomes following flow diversion in ruptured intracranial aneurysms ${ }^{\mathrm{a}}$

\begin{tabular}{|c|c|c|c|c|c|c|}
\hline \multirow{2}{*}{$\begin{array}{l}\text { Angiographic } \\
\text { Occlusion }\end{array}$} & \multicolumn{2}{|c|}{ FD } & \multicolumn{2}{|c|}{ FD and Coils } & \multicolumn{2}{|c|}{ Total } \\
\hline & Complete & Incomplete & Complete & Incomplete & Complete & Incomplete \\
\hline Overall & 74 & 4 & 23 & 7 & 97 & 11 \\
\hline \multicolumn{7}{|l|}{ Size } \\
\hline Aneurysm $<7$ mm & 44 & 3 & 10 & 1 & 54 & 4 \\
\hline Aneurysm $>7 \mathrm{~mm}$ & 10 & 1 & 12 & 5 & 22 & 6 \\
\hline \multicolumn{7}{|l|}{ Treatment timing } \\
\hline Acute treatment & 38 & 3 & 11 & 1 & 49 & 4 \\
\hline Delayed treatment & 5 & 0 & 10 & 5 & 15 & 5 \\
\hline \multicolumn{7}{|l|}{ Clinical score } \\
\hline Good clinical score & 47 & 2 & 19 & 5 & 66 & 7 \\
\hline Poor clinical score & 8 & 1 & 5 & 1 & 13 & 2 \\
\hline \multicolumn{7}{|l|}{ Location } \\
\hline Anterior circulation & 33 & 2 & 16 & 1 & 49 & 3 \\
\hline Posterior circulation & 25 & 2 & 7 & 5 & 32 & 7 \\
\hline \multicolumn{7}{|l|}{ Type } \\
\hline Dissecting & 18 & 2 & 8 & 1 & 26 & 3 \\
\hline Fusiform & 5 & 0 & 3 & 2 & 8 & 2 \\
\hline Blister & 27 & 1 & 7 & 1 & 34 & 2 \\
\hline Saccular & 7 & 1 & 7 & 3 & 14 & 4 \\
\hline Giant & 1 & 0 & 0 & 0 & 1 & 0 \\
\hline
\end{tabular}

${ }^{a}$ Data are numbers.

coiling. ${ }^{23-25}$ An FD and coils were placed in a single session in 56\% (19/34) of cases. The average size of aneurysms treated with an FD alone was $5.6 \pm 6.4 \mathrm{~mm}$, which was significantly smaller than the $10.6 \pm 6.4 \mathrm{~mm}$ average size of aneurysms treated with an FD and adjunctive coiling $(P=.001)$.

\section{Complications}

Aneurysm rerupture occurred following FD placement in 5\% $(6 / 126)$ of aneurysms, with $67 \%$ (4/6) of these reruptures occurring in aneurysms measuring $>2 \mathrm{~cm} \cdot{ }^{24-28}$ The rate of rerupture following FD placement in aneurysms of $>2 \mathrm{~cm}$ was $57 \%(4 / 7)$, which was significantly greater than the $2 \%(2 / 94)$ rate of rerupture in aneurysms of $<2 \mathrm{~cm}(P<.001)$. The rate of aneurysm rerupture with an FD alone was 6\% (5/80), which was comparable with the $3 \%(1 / 32)$ rate following FD and adjunctive coiling $(P=$ .672). Among reruptured aneurysms of $>2 \mathrm{~cm}, 75 \%$ (3/4) were treated with an FD and adjunctive coiling, while 25\% (1/4) were treated with an FD alone. Among all aneurysms that reruptured, $67 \%$ (4/6) occurred during or within the first 24 hours of treatment. No aneurysms reruptured at $>1$ week after treatment.

Hemorrhagic complications not related to aneurysm rerupture occurred in $4 \%(5 / 126)$ of patients. One was an asymptomatic cerebellar hemorrhage, ${ }^{25}$ and 2 were related to external ventricular drain placement. ${ }^{26,29}$ Two fatal hemorrhagic complications occurred, including 1 after intra-arterial tPA instillation through a microcatheter for intraprocedural thrombosis of the FD and 1 related to postprocedural hemorrhage distant from the treated aneurysm. ${ }^{26,29}$ Ischemic complications occurred in 5\% (5/111) of patients, of whom 4\% (4/111) were symptomatic, including 1 case with fatal brain stem ischemia. ${ }^{26}$

Overall, the composite rate of hemorrhagic or ischemic complications was $12 \%(15 / 126)$ because 2 complications occurred in 1 patient. ${ }^{25}$ This rate was $16 \%(10 / 62)$ in patients treated in the acute phase, compared with $0 \%(0 / 22)$ in patients treated in a delayed fashion $(P=.057)$.

\section{Angiographic Outcomes}

Complete occlusion of the aneurysm was achieved in 90\% (97/ 108) of patients on follow-up imaging (Table 1), with a median angiographic follow-up of 6 months (interquartile range, 5-6 months). Patients with a good clinical score on presentation had an occlusion rate of $90 \%(66 / 73)$, compared with patients with a poor presenting clinical score, with an occlusion rate of $87 \%$ $(13 / 15)(P=.647)$. Aneurysms in the anterior circulation demonstrated complete occlusion in $94 \%$ (49/52) of cases, which was comparable with the $82 \%(32 / 39)$ rate for aneurysms in the posterior circulation $(P=.092)$. Aneurysms treated acutely demonstrated complete occlusion in $92 \%(49 / 53)$ of cases, compared with 75\% (15/20) for aneurysms treated in a delayed fashion $(P=$ $.103)$.

Complete occlusion was achieved in 93\% (54/58) of aneurysms of $<7 \mathrm{~mm}$, compared with $79 \%$ (22/28) for aneurysms of $>7 \mathrm{~mm}(P=.072)$. In aneurysms of $<7 \mathrm{~mm}$, treatment with an FD alone resulted in complete occlusion of 94\% (44/47) of aneurysms, compared with $91 \%$ (10/11) when treated with an FD and adjunctive coiling $(P=1.000)$. In aneurysms of $>7 \mathrm{~mm}$, treatment with an FD alone resulted in complete occlusion of $91 \%$ $(10 / 11)$ of aneurysms, compared with $71 \%(12 / 17)$ when treated with FD and adjunctive coiling $(P=.355)$.

\section{Clinical Outcomes}

At last clinical follow-up, there was a favorable clinical outcome in $81 \%(101 / 124)$ of treated patients and an unfavorable clinical outcome in 19\% (23/124) (Table 2), with a median clinical follow-up of 6 months (interquartile range, $5-10$ months). In patients with a good presenting clinical score, favorable clinical outcome was $84 \%(70 / 83)$, compared with a $67 \%(10 / 15)$ rate of favorable clinical outcome in patients with poor presenting clinical scores $(P=$ .143). Favorable clinical outcome was observed in 79\% (49/62) of patients treated in the acute phase, compared with $88 \%(15 / 17)$ of patients treated in a delayed fashion $(P=.503)$. Favorable clinical 
Table 2: Clinical outcomes following flow diversion in ruptured intracranial aneurysms ${ }^{a}$

\begin{tabular}{|c|c|c|c|c|c|c|}
\hline \multirow[b]{2}{*}{ Clinical Outcome } & \multicolumn{2}{|c|}{ FD } & \multicolumn{2}{|c|}{ FD and Coils } & \multicolumn{2}{|c|}{ Total } \\
\hline & Favorable & Unfavorable & Favorable & Unfavorable & Favorable & Unfavorable \\
\hline Overall & 77 & 14 & 24 & 9 & 101 & 23 \\
\hline \multicolumn{7}{|l|}{ Size } \\
\hline Aneurysm $<7$ mm & 51 & 5 & 8 & 3 & 59 & 8 \\
\hline Aneurysm $>7 \mathrm{~mm}$ & 8 & 7 & 14 & 3 & 22 & 10 \\
\hline \multicolumn{7}{|l|}{ Treatment timing } \\
\hline Acute treatment & 41 & 9 & 8 & 4 & 49 & 13 \\
\hline Delayed treatment & 5 & 0 & 10 & 2 & 15 & 2 \\
\hline \multicolumn{7}{|l|}{ Clinical score } \\
\hline Good clinical score & 51 & 9 & 19 & 4 & 70 & 13 \\
\hline Poor clinical score & 7 & 3 & 3 & 2 & 10 & 5 \\
\hline \multicolumn{7}{|l|}{ Location } \\
\hline Anterior circulation & 39 & 7 & 14 & 3 & 53 & 10 \\
\hline Posterior circulation & 23 & 5 & 8 & 4 & 31 & 9 \\
\hline \multicolumn{7}{|l|}{ Type } \\
\hline Dissecting & 18 & 2 & 6 & 2 & 24 & 4 \\
\hline Fusiform & 4 & 3 & 4 & 1 & 8 & 4 \\
\hline Blister & 28 & 3 & 4 & 3 & 32 & 6 \\
\hline Saccular & 11 & 3 & 9 & 2 & 20 & 5 \\
\hline Giant & 1 & 1 & 0 & 1 & 1 & 2 \\
\hline
\end{tabular}

${ }^{a}$ Data are numbers.

outcome was achieved in $88 \%(59 / 67)$ of patients with treated aneurysms of $<7 \mathrm{~mm}$, compared with $69 \%$ (22/32) in patients with aneurysms of $>7 \mathrm{~mm}(P=.027)$. The use of an FD alone was associated with an $85 \%(77 / 91)$ rate of favorable clinical outcome, compared with 73\% (24/33) for aneurysms treated with an FD and adjunctive coiling $(P=.189)$. In aneurysms of $<7 \mathrm{~mm}$, treatment with an FD alone resulted in favorable outcome in $91 \%$ $(51 / 56)$ of cases, compared with $73 \%(8 / 11)$ when treated with an FD and adjunctive coiling $(P=.117)$. In aneurysms of $>7 \mathrm{~mm}$, treatment with an FD alone resulted in favorable outcome in 53\% $(8 / 15)$ of cases, compared with $82 \%(14 / 17)$ when treated with an FD and adjunctive coiling $(P=.128)$. Favorable clinical outcome was achieved in $84 \%(53 / 63)$ of patients with aneurysms in the anterior circulation, compared with $78 \%(31 / 40)$ of patients with aneurysms in the posterior circulation $(P=.441)$.

\section{DISCUSSION}

Endovascular coil embolization and open microsurgical clipping are the traditional methods for treatment of ruptured intracranial aneurysms. Recently, newer endovascular devices such as FDs have also been used to treat ruptured intracranial aneurysms. In this meta-analysis of case series and reports, we found that $81 \%$ of patients with ruptured aneurysms treated with FDs had favorable clinical outcomes, which is comparable with the number of patients with similar outcomes in large trials such as ISAT. ${ }^{4}$ Thus, FDs may present a viable treatment option for ruptured intracranial aneurysms that are not readily amenable to first-line treatments such as coil embolization or clipping.

Nevertheless, the use of FDs for ruptured intracranial aneurysms is controversial because dual antiplatelet therapy and the delayed nature of aneurysm thrombosis may both increase the likelihood and severity of hemorrhagic complications during and after treatment. Indeed, our meta-analysis identified a 9\% composite rate of intracranial hemorrhagic complications, including $5 \%$ from aneurysm rerupture and $4 \%$ from other causes. Complication-induced neurologic morbidity is not well-defined, ${ }^{30}$ however, because some of these complications did not produce new symptoms. Notably, hemorrhagic complications following other procedures (eg, tracheostomy, extraventricular drainage, ${ }^{26,29}$ and ventriculoperitoneal shunt placement) are included in the $4 \%$ of patients with nonaneurysmal hemorrhagic complications. In addition to hemorrhagic complications, there was a $4 \%$ rate of symptomatic ischemic complications, though the rate of asymptomatic or undetected ischemic events is likely higher. ${ }^{24-26,29,31}$

At least part of the risk of hemorrhagic complications appears to be related to aneurysm size. It has been proposed that reduction of local vascular compliance after FD placement may exaggerate the "Windkessel effect" 32 and result in increased vessel flow distal to the aneurysm, which may lead to intraparenchymal hemorrhage after flow diversion. ${ }^{33,34}$ This phenomenon may be amplified in giant aneurysms ${ }^{33}$ because increased distal vessel wall shear stress and increased intra-aneurysmal pressure ${ }^{35}$ heighten the risk of aneurysm rerupture after flow diversion. Indeed, in this metaanalysis, aneurysms of $>2 \mathrm{~cm}$ were significantly more likely than smaller aneurysms to rerupture after treatment, even though the natural rate of aneurysm rerupture in giant aneurysms is similar to that in smaller lesions. ${ }^{36}$ These results, along with overall improved angiographic and clinical outcomes in aneurysms of $<7$ $\mathrm{mm}$, suggest that FD-based treatment is more effective for small aneurysms. If larger aneurysms must be treated with FDs, then adjunctive coiling is likely worthwhile. ${ }^{25,37,38}$ Alternatively, a staged treatment strategy of initial coiling followed by later FD placement may be appropriate in this setting because rebleeding has not been observed between procedures. ${ }^{39}$ In these cases, loose packing of the aneurysm dome may be sufficient to accelerate aneurysm thrombosis ${ }^{26,38}$ without producing a mass effect on the FD that could result in device thrombosis. ${ }^{40}$

In general, ruptured aneurysms in the posterior circulation carry an overall poorer prognosis than those in the anterior circulation. ${ }^{41}$ Furthermore, FD placement in the posterior circula- 
tion is associated with a higher rate of ischemic complications. ${ }^{42}$ In this meta-analysis, however, there was no appreciable difference in the rate of complete angiographic occlusion or good clinical outcome between aneurysms in the anterior circulation and those in the posterior circulation.

Despite the importance of antiplatelet therapy on the success of FD-based interventions, there is wide variability in antiplatelet management surrounding the use of FDs in aneurysmal subarachnoid hemorrhage. For example, some authors reported performing invasive procedures (eg, extraventricular drain or central line placement) 12 hours before FD placement or dual antiplatelet inhibition, administering a loading dose of aspirin and clopidogrel before FD placement and continuing dual antiplatelet therapy for at least 3 months. ${ }^{26}$ Other authors avoided preprocedural antiplatelet therapy altogether, instead administering aspirin, clopidogrel, and a glycoprotein IIb/IIIa inhibitor during FD placement, followed by a 12-hour maintenance infusion of a glycoprotein IIb/IIIa inhibitor and postprocedural dual antiplatelet therapy for 6 months. ${ }^{27}$

This study has several limitations. First, the lack of independent clinical and angiographic assessment and the potential for reporting bias in the included studies may affect the estimated rates of angiographic occlusion and favorable clinical outcome. Second, reporting of procedural details, aneurysm characteristics, angiographic follow-up, and outcome data was not uniform across all studies. As a result, we used composite measures (eg, good clinical outcome instead of specific mRS scores) that may partially obscure underlying details. Third, details describing the administration and monitoring of antiplatelet therapy during the periprocedural period was variable and infrequently specified. Finally, despite an overall large number of cases represented in this meta-analysis, the smaller number of cases in some subgroups (particularly those for which FD-based treatment is unlikely to be strongly considered, such as very large aneurysms) may not provide sufficient power to discriminate small effect sizes. We suspect that this effect may account for the inability to demonstrate a statistically significant difference in the rate of occlusion between small and large aneurysms or between aneurysms treated with an FD alone and those treated with an FD and adjunctive coiling.

\section{CONCLUSIONS}

Endovascular coil embolization and microsurgical clipping are likely to remain the first-line treatment of ruptured intracranial aneurysms, but when these options are not feasible, the use of FDs and appropriate dual antiplatelet therapy can allow a high rate of angiographic occlusion and a reasonable likelihood of good clinical outcome. However, one must be cognizant of the possibility that FDs may not be protective against rerupture in aneurysms of $>2 \mathrm{~cm}$. Clinical outcomes associated with FD treatment of ruptured aneurysms appear most favorable for aneurysms of $<7 \mathrm{~mm}$.

Disclosures: Christopher J. Moran—UNRELATED: Consultancy: Medtronic; Grants/ Grants Pending: Medtronic*; Payment for Lectures including Service on Speakers Bureaus: Medtronic; Payment for Development of Educational Presentations: Medtronic. *Money paid to the institution.

\section{REFERENCES}

1. Guglielmi G, Viñuela F, Dion J, et al. Electrothrombosis of saccular aneurysms via endovascular approach, Part 2: preliminary clinical experience. J Neurosurg 1991;75:8-14 Medline

2. Wiebers DO, Whisnant JP, Huston J 3rd, International Study of Unruptured Intracranial Aneurysms Investigators. Unruptured intracranial aneurysms: natural history, clinical outcome, and risks of surgical and endovascular treatment. Lancet 2003;362:103-10 CrossRef Medline

3. Pierot L, Spelle L, Vitry F, et al; ATENA Investigators. Immediate clinical outcome of patients harboring unruptured intracranial aneurysms treated by endovascular approach: results of the ATENA study. Stroke 2008;39:2497-504 CrossRef Medline

4. Molyneux A, Kerr R, Stratton I; International Subarachnoid Aneurysm Trial (ISAT) Collaborative Group. International Subarachnoid Aneurysm Trial (ISAT) of neurosurgical clipping versus endovascular coiling in 2143 patients with ruptured intracranial aneurysms: a randomised trial. Lancet 2002;360:1267-74 CrossRef Medline

5. McDougall CG, Spetzler RF, Zabramski JM, et al. The Barrow Ruptured Aneurysm Trial. J Neurosurg 2012;116:135-44 CrossRef Medline

6. Brilstra EH, Rinkel GJ, Algra A, et al. Rebleeding, secondary ischemia, and timing of operation in patients with subarachnoid hemorrhage. Neurology 2000;55:1656-60 CrossRef Medline

7. Koivisto T, Vanninen R, Hurskainen H, et al. Outcomes of early endovascular versus surgical treatment of ruptured cerebral aneurysms: a prospective randomized study. Stroke 2000;31: 2369-77 CrossRef Medline

8. Yu SC, Kwok CK, Cheng PW, et al. Intracranial aneurysms: midterm outcome of Pipeline embolization device-a prospective study in 143 patients with 178 aneurysms. Radiology 2012;265:893901 CrossRef Medline

9. Zhu Y, Pan J, Shen J, et al. Clinical and radiological outcomes after treatment of unruptured paraophthalmic internal carotid artery aneurysms: a comparative and pooled analysis of single-center experiences. World Neurosurg 2015;84:1726-38 CrossRef Medline

10. Becske T, Kallmes DF, Saatci I, et al. Pipeline for uncoilable or failed aneurysms: results from a multicenter clinical trial. Radiology 2013; 267:858-68 CrossRef Medline

11. Petr $\mathrm{O}$, Brinjikji W, Cloft $\mathrm{H}$, et al. Current trends and results of endovascular treatment of unruptured intracranial aneurysms at a single institution in the flow-diverter era. AJNR Am J Neuroradiol 2016;37:1106-13 CrossRef Medline

12. Di Maria F, Pistocchi S Clarençon F, et al. Flow diversion versus standard endovascular techniques for the treatment of unruptured carotid-ophthalmic aneurysms. AJNR Am J Neuroradiol 2015;36: 2325-30 CrossRef Medline

13. Kühn AL, Hou SY, Perras M, et al. Flow diverter stents for unruptured saccular anterior circulation perforating artery aneurysms: safety, efficacy, and short-term follow-up. J Neurointerv Surg 2015; 7:634-40 CrossRef Medline

14. Tanweer O, Raz E, Brunswick A, et al. Cavernous carotid aneurysms in the era of flow diversion: a need to revisit treatment paradigms. AJNR Am J Neuroradiol 2014;35:2334-40 CrossRef Medline

15. Chalouhi N, Starke RM, Yang S, et al. Extending the indications of flow diversion to small, unruptured, saccular aneurysms of the anterior circulation. Stroke 2014;45:54-58 CrossRef Medline

16. Chalouhi N, Tjoumakaris S, Starke RM, et al. Comparison of flow diversion and coiling in large unruptured intracranial saccular aneurysms. Stroke 2013;44:2150-54 CrossRef Medline

17. Kallmes DF, Hanel R, Lopes D, et al. International retrospective study of the Pipeline embolization device: a multicenter aneurysm treatment study. AJNR Am J Neuroradiol 2015;36:108-15 CrossRef Medline

18. Fiorella D, Hsu D, Woo HH, et al. Very late thrombosis of a Pipeline embolization device construct: case report. Neurosurgery 2010;67(3 suppl operative):onsE313-14; discussion onsE314 CrossRef Medline 
19. Saatci I, Yavuz K, Ozer C, et al. Treatment of intracranial aneurysms using the Pipeline flow-diverter embolization device: a single-center experience with long-term follow-up results. AJNR Am J Neuroradiol 2012;33:1436-46 CrossRef Medline

20. Fischer S, Vajda Z, Aguilar Perez M, et al. Pipeline embolization device (PED) for neurovascular reconstruction: initial experience in the treatment of 101 intracranial aneurysms and dissections. Neuroradiology 2012;54:369-82 CrossRef Medline

21. Proust F, Hannequin D, Langlois $\mathrm{O}$, et al. Causes of morbidity and mortality after ruptured aneurysm surgery in a series of 230 patients: the importance of control angiography. Stroke 1995;26: 1553-57 CrossRef Medline

22. Riley RD, Lambert PC, Abo-Zaid G. Meta-analysis of individual participant data: rationale, conduct, and reporting. BMJ 2010;340:c221 CrossRef Medline

23. Çinar C, Oran İ, Bozkaya H, et al. Endovascular treatment of ruptured blister-like aneurysms with special reference to the flowdiverting strategy. Neuroradiology 2013;55:441-47 CrossRef Medline

24. Cruz JP, O’Kelly C, Kelly M, et al. Pipeline embolization device in aneurysmal subarachnoid hemorrhage. AJNR Am J Neuroradiol 2013;34:271-76 CrossRef Medline

25. McAuliffe W, Wenderoth JD. Immediate and midterm results following treatment of recently ruptured intracranial aneurysms with the Pipeline embolization device. AJNR Am J Neuroradiol 2012;33: 487-93 CrossRef Medline

26. Lin N, Brouillard AM, Keigher KM, et al. Utilization of Pipeline embolization device for treatment of ruptured intracranial aneurysms: US multicenter experience. J Neurointerv Surg 2015;7: 808-15 CrossRef Medline

27. Chalouhi N, Zanaty M, Whiting A, et al. Treatment of ruptured intracranial aneurysms with the Pipeline embolization device. $\mathrm{Neu}$ rosurgery 2015;76:165-72; discussion 172 CrossRef Medline

28. Nerva JD, Morton RP, Levitt MR, et al. Pipeline embolization device as primary treatment for blister aneurysms and iatrogenic pseudoaneurysms of the internal carotid artery. J Neurointerv Surg 2015; 7:210-16 CrossRef Medline

29. Yoon JW, Siddiqui AH, Dumont TM, et al; Endovascular Neurosurgery Research Group. Feasibility and safety of Pipeline embolization device in patients with ruptured carotid blister aneurysms. Neurosurgery 2014;75:419-29; discussion 429 CrossRef Medline

30. Mahaney KB, Chalouhi N, Viljoen S, et al. Risk of hemorrhagic complication associated with ventriculoperitoneal shunt placement in aneurysmal subarachnoid hemorrhage patients on dual antiplatelet therapy. J Neurosurg 2013;119:937-42 CrossRef Medline
31. Brasiliense LB, Stanley MA, Grewal SS, et al. Silent ischemic events after Pipeline embolization device: a prospective evaluation with MR diffusion-weighted imaging. J Neurointerv Surg 2016;8:11361139 CrossRef Medline

32. Chiu AHY, Wenderoth J. Cerebral hyperperfusion after flow diversion of large intracranial aneurysms. J Neurointerv Surg 2013;5:e48 CrossRef Medline

33. Velat GJ, Fargen KM, Lawson MF, et al. Delayed intraparenchymal hemorrhage following Pipeline embolization device treatment for a giant recanalized ophthalmic aneurysm. J Neurointerv Surg 2012;4: e24 CrossRef Medline

34. Cruz J, Chow M, O’Kelly C, et al. Delayed ipsilateral parenchymal hemorrhage following flow diversion for the treatment of anterior circulation aneurysms. AJNR Am J Neuroradiol 2012;33:603-08 CrossRef Medline

35. Cebral J, Mut F, Raschi M, et al. Aneurysm rupture following treatment with flow-diverting stents: computational hemodynamics analysis of treatment. AJNR Am J Neuroradiol 2011;32:27-33 CrossRef Medline

36. Khurana VG, Piepgras DG, Whisnant JP. Ruptured giant intracranial aneurysms, Part I: a study of rebleeding. J Neurosurg 1998;88: 425-29 CrossRef Medline

37. Park MS, Kilburg C, Taussky P, et al. Pipeline embolization device with or without adjunctive coil embolization: analysis of complications from the IntrePED Registry. AJNR Am J Neuroradiol 2016;37: 1127-31 CrossRef Medline

38. Lin N, Brouillard AM, Krishna C, et al. Use of coils in conjunction with the Pipeline embolization device for treatment of intracranial aneurysms. Neurosurgery 2015;76:142-49 CrossRef Medline

39. Brinjikji W, Piano M, Fang S, et al. Treatment of ruptured complex and large/giant ruptured cerebral aneurysms by acute coiling followed by staged flow diversion. J Neurosurg 2016;125:120-27 CrossRef Medline

40. Siddiqui AH, Kan $\mathrm{P}$, Abla AA, et al. Complications after treatment with Pipeline embolization for giant distal intracranial aneurysms with or without coil embolization. Neurosurgery 2012;71:E509-13; discussion E513 CrossRef Medline

41. Schievink WI, Wijdicks EF, Piepgras DG, et al. The poor prognosis of ruptured intracranial aneurysms of the posterior circulation. J Neurosurg 1995;82:791-95 CrossRef Medline

42. Brinjikji W, Murad MH, Lanzino G, et al. Endovascular treatment of intracranial aneurysms with flow diverters a meta-analysis. Stroke 2013;44:442-47 CrossRef Medline 